\title{
Low preoperative lymphocyte to monocyte ratio predicts poor cancer-specific survival in patients with esophageal squamous cell carcinoma
}

This article was published in the following Dove Press journal:

OncoTargets and Therapy

8 January 2015

Number of times this article has been viewed

Ying Huang'
Ji-Feng Feng

'Department of Operating Theatre, Zhejiang Cancer Hospital, Hangzhou, People's Republic of China;

${ }^{2}$ Department of Thoracic Surgery, Zhejiang Cancer Hospital, Hangzhou, People's Republic of China
Correspondence: ji-Feng Feng

Department of Thoracic Surgery,

Zhejiang Cancer Hospital,

No 38 Guangji Road, Hangzhou 310022,

People's Republic of China

Tel +86 57I 88I2 8052

Email jifzhejiang@gmail.com
Background: Recent studies have shown that the lymphocyte to monocyte ratio (LMR) is a useful predictive factor in various cancers. However, the prognostic value of LMR in patients with esophageal cancer has not been reported yet. The purpose of the current study was to determine the prognostic role of LMR in esophageal squamous cell carcinoma (ESCC).

Methods: Three-hundred and forty-eight patients who had undergone esophagectomy for ESCC were included. A receiver operating characteristic curve for survival prediction was plotted to verify the optimum cut-off point for LMR. Kaplan-Meier method was used to calculate the cancer-specific survival (CSS), the difference was assessed by the log-rank test. Univariate and multivariate analyses were performed to evaluate the prognostic factors.

Results: A receiver operating characteristic curve for survival prediction was plotted to verify the optimum cut-off point for LMR, which was 2.93. Patients with LMR $\leq 2.93$ had a significantly worse 5-year CSS than patients with LMR $>2.93(21.2 \%$ versus $59.3 \%, P<0.001)$. For subgroup analysis, the predictive value of LMR was also significant in patients with T1-2 cancer $(P=0.003)$, T3-4a $(P<0.001)$, and patients with $(P=0.044)$ or without $(P<0.001)$ nodal metastasis. In addition, the predictive value of LMR was also significant stratified by absolute lymphocyte count $(P<0.001)$ and absolute monocyte count $(P<0.001)$. In multivariate analysis, LMR was a significant predictive factor of CSS $(P=0.010)$.

Conclusion: LMR is still a predictive factor for long-term survival in patients with ESCC. We conclude that 2.93 may be the optimum cut-off point for LMR in predicting survival in ESCC patients.

Keywords: esophageal cancer, squamous cell carcinoma, prognostic factor, lymphocyte to monocyte ratio, cancer-specific survival

\section{Introduction}

Squamous cell carcinoma (SCC) and adenocarcinoma (AC) are the two most common histologic types of esophageal cancer (EC). ${ }^{1,2}$ In People's Republic of China, SCC accounts for more than $95 \%$ of EC, in contrast to the predominance of $\mathrm{AC}$ in the West. ${ }^{3,4}$ Although advances have occurred in comprehensive therapy, patients with EC still has a poor prognosis due to late diagnosis, rapid growth, and high recurrence rate. ${ }^{5,6}$ There are important biological differences between SCC and AC, therefore, a prognostic study that takes into account the predominance of SCC in People's Republic of China is more and more important.

It is well known that systemic inflammatory response plays an important role in cancer progression. ${ }^{7,8}$ The systemic inflammatory response, which is usually measured by peripheral blood-based parameters, such as C-reactive protein, neutrophil, lymphocyte or platelet count, has been shown to be a predictive factor in various cancers, including 
ECs. ${ }^{9,10}$ Moreover, lymphocyte to monocyte ratio (LMR) is another inflammatory marker. Recently studies demonstrated that LMR is associated with prognosis in several cancers, such as hematological malignancy, colon cancer, and lung cancer. ${ }^{11-13}$ However, to the best of our knowledge, no studies regarding the predictive value of LMR in patients with EC are available. Therefore, the aim of this study was to investigate the prognostic role of LMR in patients with esophageal squamous cell carcinoma (ESCC).

\section{Patients and methods}

During the period between January 2006 and December 2008, a retrospective analysis was conducted on 348 patients with ESCC who underwent surgery at Zhejiang Cancer Hospital (Hangzhou, People's Republic of China). The inclusion criteria were as follows: 1) patients with ESCC confirmed by histopathology with curative esophagectomy; 2) patients who had not received neoadjuvant chemotherapy and/or radiotherapy, and 3) preoperative blood test results were obtained within 1 week prior to surgery. Ethical approval was obtained from the Ethical Committees of Zhejiang Cancer Hospital.

All patients were treated with radical esophagectomy. Patients who had received preoperative neoadjuvant therapy (chemotherapy and/or radiotherapy) were excluded from our study. During that period, the role of postoperative adjuvant chemoradiotherapy was controversial, therefore, adjuvant therapy was not mandatory.

Data on preoperative blood cell counts were extracted from our medical records. All white blood cell and differential counts (including lymphocyte count and monocyte count) were taken within 1 week prior to surgery. In this study, the LMR was defined as the absolute lymphocyte count (ALC) divided by the absolute monocyte count (AMC).

\section{Statistical analysis}

Statistical analysis was conducted with SPSS 17.0 (SPSS Inc., Chicago, IL, USA). As this series described the prognosis of patients with ESCC, a cancer-specific survival (CSS) analysis would be more appropriate. The CSS was defined as the time from surgery to cancer-related death. A receiver operating characteristic (ROC) curve for CSS prediction was plotted to verify the optimum cut-off point for LMR, ALC, and AMC. Independent Student's $t$-test was used to compare groups of continuous LMR. Chi-squared test was used to determine the significance of differences for dichotomous LMR. Pearson correlation analysis was used to determine the correlation of LMR, ALC, and AMC. The CSS was calculated by the Kaplan-Meier method, and the difference was assessed by the log-rank test. A univariate analysis was used to examine the association between various prognostic predictors and CSS. Possible prognostic factors associated with CSS were considered in a multivariable Cox proportional hazards regression analysis. A $P$-value less than 0.05 was considered to be statistically significant.

\section{Results}

The baseline characteristics are shown in Table 1. Among the 348 patients, 45 (12.9\%) were women and 303 (87.1\%) were men. The mean age was $59.2 \pm 7.8$ years (range $38-80$ years). The histograms of ALC, AMC, and LMR are shown in Figure 1. The mean ALC and AMC were 1.67 $\pm 0.66\left(\times 10^{9} / \mathrm{L}\right)$ and $0.70 \pm 0.41\left(\times 10^{9} / \mathrm{L}\right)$, respectively, with a mean LMR of 3.51 \pm 3.44 . There were significant positive correlations between ALC and AMC ( $r=0.345, P<0.001$, Figure 2A), ALC and LMR ( $r=0.174, P=0.001$, Figure $2 \mathrm{~B}$ ). However, there were significant negative correlations between AMC and LMR ( $r=-0.490, P<0.001$, Figure $2 \mathrm{C}$ ).

Table I The baseline characteristics in patients with ESCC

\begin{tabular}{|c|c|}
\hline & Cases (n, \%) \\
\hline Age (mean $\pm S D$, years) & $59.2 \pm 7.8$ \\
\hline$\leq 60$ & $198(56.9)$ \\
\hline$>60$ & $150(43.1)$ \\
\hline \multicolumn{2}{|l|}{ Sex } \\
\hline Female & $45(12.9)$ \\
\hline Male & $303(87.1)$ \\
\hline Tumor length (mean $\pm \mathrm{SD}, \mathrm{cm}$ ) & $4.35 \pm 1.85$ \\
\hline$\leq 3.0$ & $92(26.4)$ \\
\hline$>3.0$ & $256(73.6)$ \\
\hline \multicolumn{2}{|l|}{ Tumor location } \\
\hline Upper & $18(5.2)$ \\
\hline Middle & $168(48.3)$ \\
\hline Lower & $162(46.5)$ \\
\hline \multicolumn{2}{|l|}{ Differentiation } \\
\hline Well & $50(14.4)$ \\
\hline Moderate & $225(64.7)$ \\
\hline Poor & $73(20.9)$ \\
\hline \multicolumn{2}{|l|}{ Depth of invasion } \\
\hline TI & $60(17.2)$ \\
\hline $\mathrm{T} 2$ & $54(15.5)$ \\
\hline T3 & $196(56.3)$ \\
\hline $\mathrm{T} 4 \mathrm{a}$ & $38(11.0)$ \\
\hline \multicolumn{2}{|l|}{ Nodal metastasis } \\
\hline Negative & $179(5 \mathrm{I} .4)$ \\
\hline Positive & $169(48.6)$ \\
\hline $\operatorname{ALC}\left(\right.$ mean $\left.\pm S D, \times 10^{9} / L\right)$ & $1.67 \pm 0.66$ \\
\hline $\mathrm{AMC}\left(\right.$ mean $\left.\pm \mathrm{SD}, \times 10^{9} / \mathrm{L}\right)$ & $0.70 \pm 0.4 \mathrm{I}$ \\
\hline LMR (mean \pm SD) & $3.5 \mathrm{I} \pm 3.44$ \\
\hline
\end{tabular}

Abbreviations: ESCC, esophageal squamous cell carcinoma; SD, standard deviation; ALC, absolute lymphocyte count; AMC, absolute monocyte count; LMR, lymphocyte to monocyte ratio. 

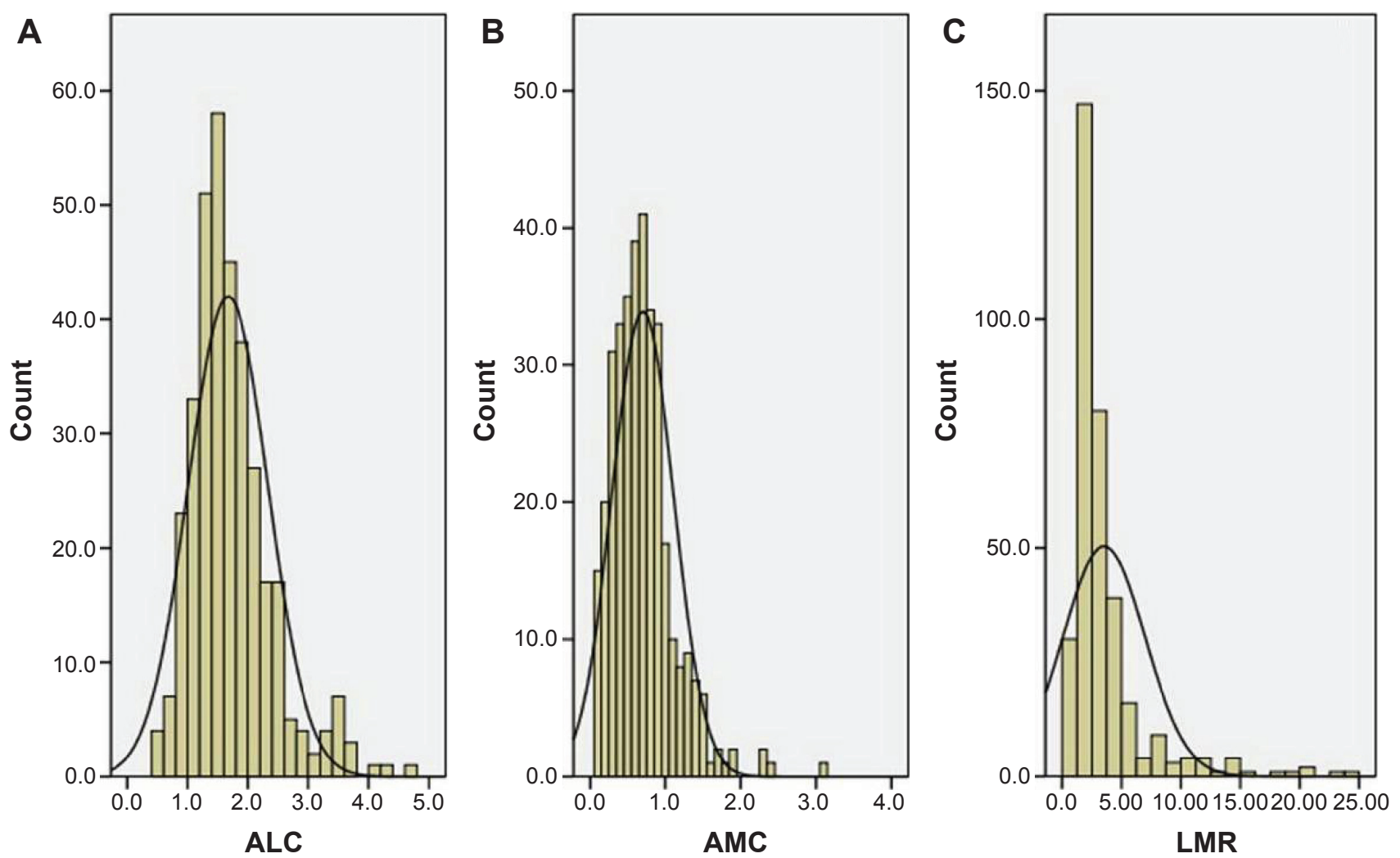

Figure I The histograms of the ALC (A), AMC (B), and LMR (C).

Abbreviations: ALC, absolute lymphocyte count; AMC, absolute monocyte count; LMR, lymphocyte to monocyte ratio.
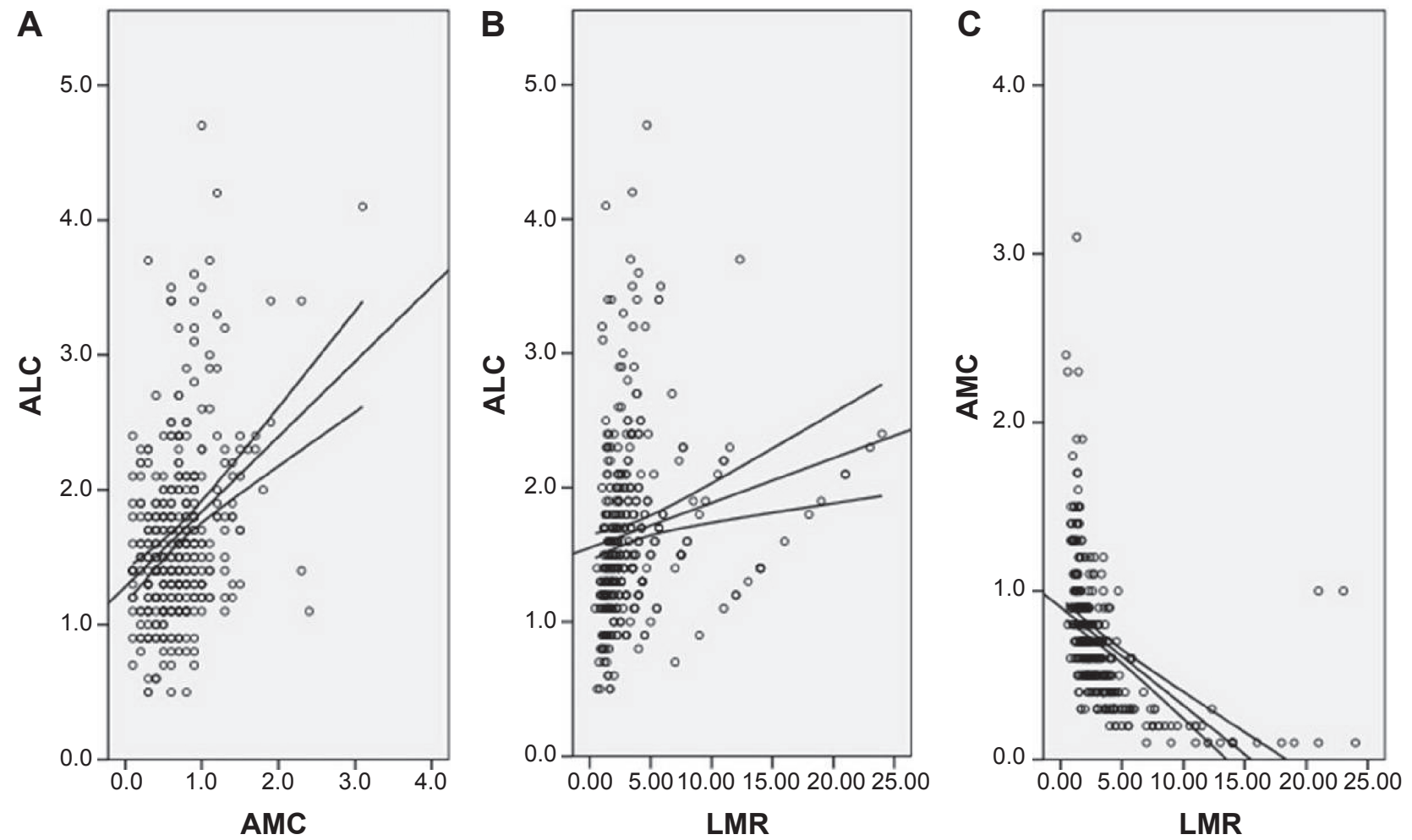

Figure 2 Positive correlations between ALC and AMC (A), ALC and LMR (B). Negative correlation between AMC and LMR (C). Abbreviations: ALC, absolute lymphocyte count; AMC, absolute monocyte count; LMR, lymphocyte to monocyte ratio. 
ROC curves for survival prediction (CSS) were plotted to verify the optimum cut-off points for ALC, AMC, and LMR, which were $1.75\left(\times 10^{9} / \mathrm{L}\right), 0.55\left(\times 10^{9} / \mathrm{L}\right)$, and 2.93 , respectively (Figure 3 ). Based on the cut-off value of LMR, patients were then divided into two groups for further analysis (patients with LMR $\leq 2.93$ and patients with LMR > 2.93). Overall, there were 203 (58.3\%) patients with LMR $\leq 2.93$ and $145(41.7 \%)$ patients with LMR $>2.93$. Our study showed that LMR was associated with tumor length $(P=0.033)$, depth

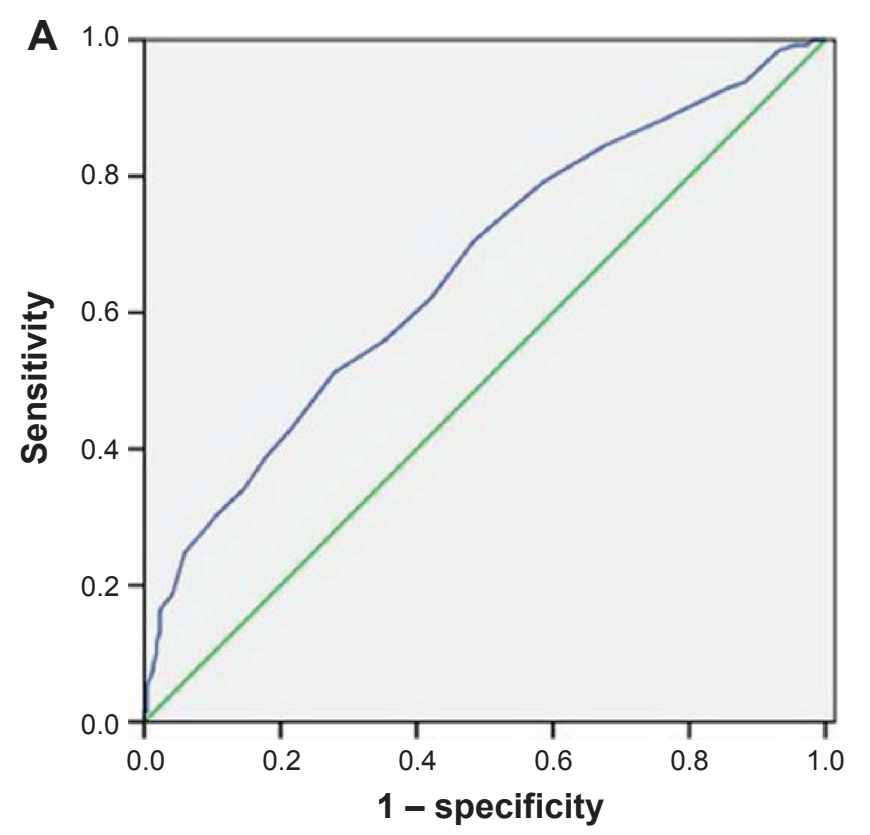

of invasion $(P=0.015)$, nodal metastasis $(P=0.007)$, ALC $(P<0.001)$, and AMC $(P<0.001)$ (Table 2$)$.

Patients with LMR $\leq 2.93$ had a significantly worse 5 -year CSS than patients with LMR $>2.93(21.2 \%$ versus $59.3 \%$, $P<0.001$ ) (Figure 4A). In addition, there were also significant differences in 5-year CSS regarding ALC (52.0\% versus $28.5 \%$, $P<0.001$, Figure 4B) and AMC (48.6\% versus $28.9 \%, P<0.001$, Figure 4 C). For subgroup analysis, the predictive value of LMR was significant in patients with T1-2 cancer $(P=0.003)$, T3-4a

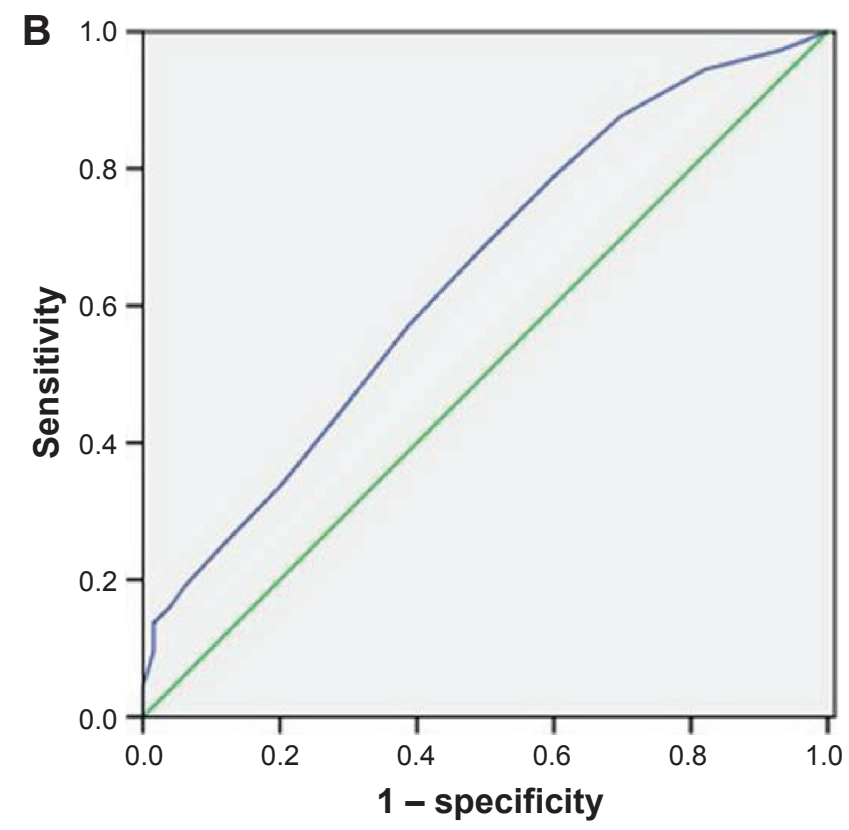

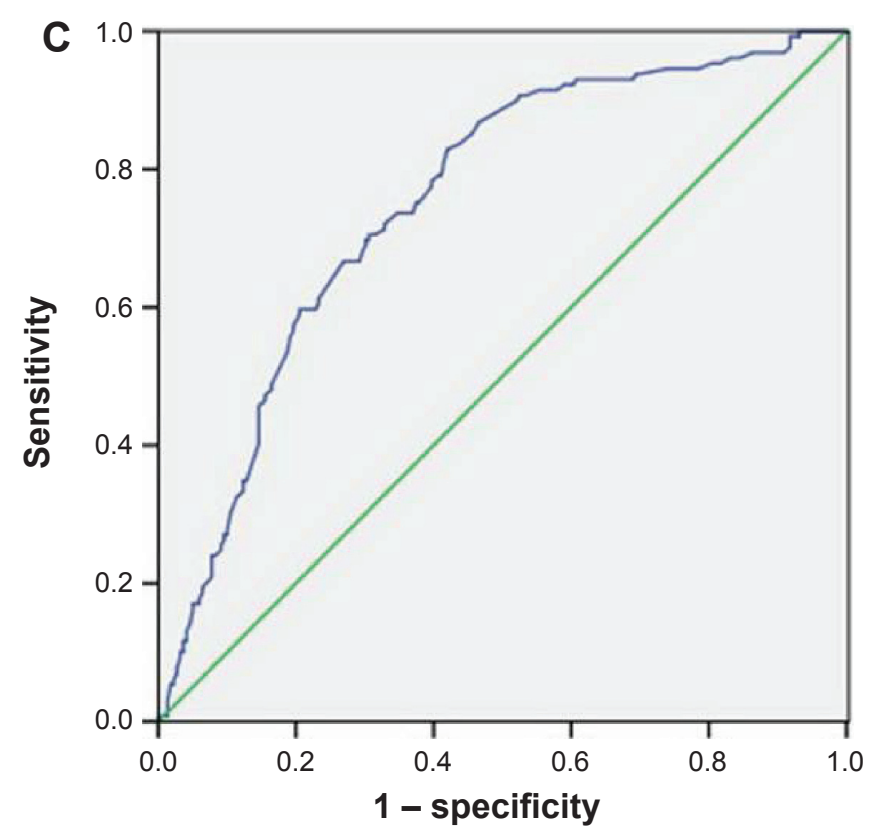

Figure 3 ROC curves for survival prediction (CSS) were plotted to verify the optimum cut-off points for ALC (A), AMC (B), and LMR (C).

Abbreviations: ROC, receiver operating characteristic; CSS, cancer-specific survival; ALC, absolute lymphocyte count; AMC, absolute monocyte count; LMR, lymphocyte to monocyte ratio.

Notes: Reference line (green); ROC line (blue). 
Table 2 Comparison of baseline clinical characteristics based on LMR

\begin{tabular}{|c|c|c|c|c|}
\hline & Cases (n, \%) & LMR $\leq 2.93(n, \%)$ & LMR $>2.93(n, \%)$ & $P$-value \\
\hline Age (years) & & & & 0.583 \\
\hline$\leq 60$ & $198(56.9)$ & II $3(55.7)$ & $85(58.6)$ & \\
\hline$>60$ & $150(43.1)$ & $90(44.3)$ & $60(4 I .4)$ & \\
\hline Sex & & & & 0.168 \\
\hline Female & $45(12.9)$ & $22(10.8)$ & $23(15.9)$ & \\
\hline Male & $303(87.1)$ & $181(89.2)$ & $122(84.1)$ & \\
\hline Tumor length $(\mathrm{cm})$ & & & & 0.033 \\
\hline$\leq 3$ & $92(26.4)$ & $45(22.2)$ & $47(32.4)$ & \\
\hline$>3$ & $256(73.6)$ & I 58 (77.8) & $98(67.6)$ & \\
\hline Tumor location & & & & 0.207 \\
\hline Upper & $18(5.2)$ & $12(5.9)$ & $6(4.1)$ & \\
\hline Middle & $168(48.3)$ & $90(44.3)$ & $78(53.8)$ & \\
\hline Lower & $162(46.5)$ & I0I (49.8) & $61(42.1)$ & \\
\hline Vessel invasion & & & & 0.200 \\
\hline Negative & $292(83.9)$ & $166(81.8)$ & $126(86.9)$ & \\
\hline Positive & $56(16.1)$ & $37(18.2)$ & $19(13.1)$ & \\
\hline Differentiation & & & & 0.809 \\
\hline Well & $50(14.4)$ & $29(14.3)$ & $21(14.5)$ & \\
\hline Moderate & $225(64.7)$ & $129(63.5)$ & $96(66.2)$ & \\
\hline Poor & $73(20.9)$ & $45(22.2)$ & $28(19.3)$ & \\
\hline Depth of invasion & & & & 0.015 \\
\hline TI-2 & II 4 (32.8) & $56(27.6)$ & $58(40.0)$ & \\
\hline T3-4a & $234(67.5)$ & $147(72.4)$ & $87(60.0)$ & \\
\hline Nodal metastasis & & & & 0.007 \\
\hline Negative & $179(5 \mid .4)$ & $92(45.3)$ & $87(60.0)$ & \\
\hline Positive & $169(48.6)$ & II I (54.7) & $58(40.0)$ & \\
\hline Adjuvant therapy & & & & 0.953 \\
\hline No & $243(69.8)$ & $142(70.0)$ & I0I (69.7) & \\
\hline Yes & $105(30.2)$ & $61(30.0)$ & $44(30.3)$ & \\
\hline $\operatorname{ALC}\left(\times 10^{\%} / \mathrm{L}\right)$ & & & & $<0.001$ \\
\hline$\leq 1.75$ & $221(63.5)$ & 149 (73.4) & $72(49.7)$ & \\
\hline$>1.75$ & $127(36.5)$ & $54(26.6)$ & $73(50.3)$ & \\
\hline AMC $\left(\times 10^{9} / L\right)$ & & & & $<0.001$ \\
\hline$\leq 0.55$ & | 44 (4|.4) & $36(17.7)$ & $108(74.5)$ & \\
\hline$>0.55$ & $204(58.6)$ & $167(82.3)$ & $37(25.5)$ & \\
\hline
\end{tabular}

Abbreviations: ALC, absolute lymphocyte count; AMC, absolute monocyte count; LMR, lymphocyte to monocyte ratio.

$(P<0.001)$, and patients with $(P=0.044)$ or without $(P<0.001)$ nodal metastasis (Figure 5). In addition, the predictive value of LMR was also significantly stratified by $\operatorname{ALC}(P<0.001)$ and AMC $(P<0.001)$ (Figure 6).

By univariate analysis, we found that tumor length, vessel invasion, depth of invasion, nodal metastasis, ALC, AMC, and LMR had significant associations with CSS. Then multivariate Cox proportional hazards model demonstrated that LMR was an independent prognostic factor in patients with ESCC (Table 3 ). LMR $>2.93$ had a hazard ratio of 0.60 (95\% confidence interval: $0.407-0.885, P=0.010$ ) for CSS (Table 3).

\section{Discussion}

To the best of our knowledge, this is the first study to determine the prognostic value of LMR in predicting postoperative prognosis for patients with ESCC. Our study showed that LMR is associated with tumor progression and can be considered as an independent predictive marker of prognosis in patients with ESCC. We used an ROC curve for survival prediction to verify the optimal cut-off point for LMR, and concluded the value of 2.93 may be the optimum cut-off point for LMR in predicting prognosis in ESCC patients.

In our study, we analyzed the potential prognostic role of LMR in ESCC patients who had not received neoadjuvant chemoradiotherapy mainly because chemotherapy and/or radiation will have an important impact on the systemic inflammation. Several different hematological indexes have shown prognostic significance in patients with EC. ${ }^{14-16}$ Recent studies have shown a strong link between cancer and inflammation. Several peripheral inflammatory cells, such as neutrophils, 

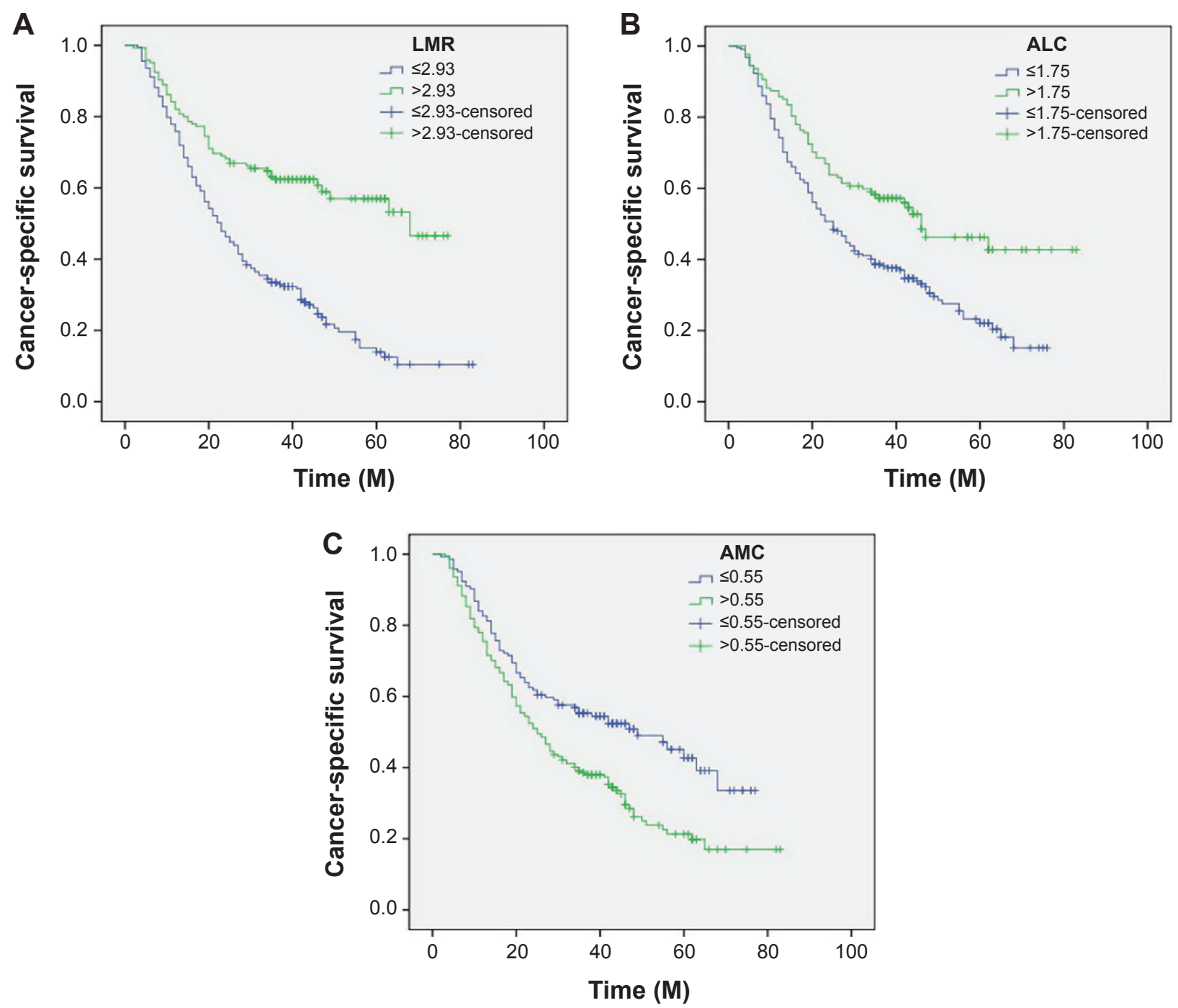

Figure 4 Kaplan-Meier CSS curves stratified by LMR (A), ALC (B), and AMC (C).

Abbreviations: CSS, cancer-specific survival; ALC, absolute lymphocyte count; AMC, absolute monocyte count; LMR, lymphocyte to monocyte ratio; M, months.
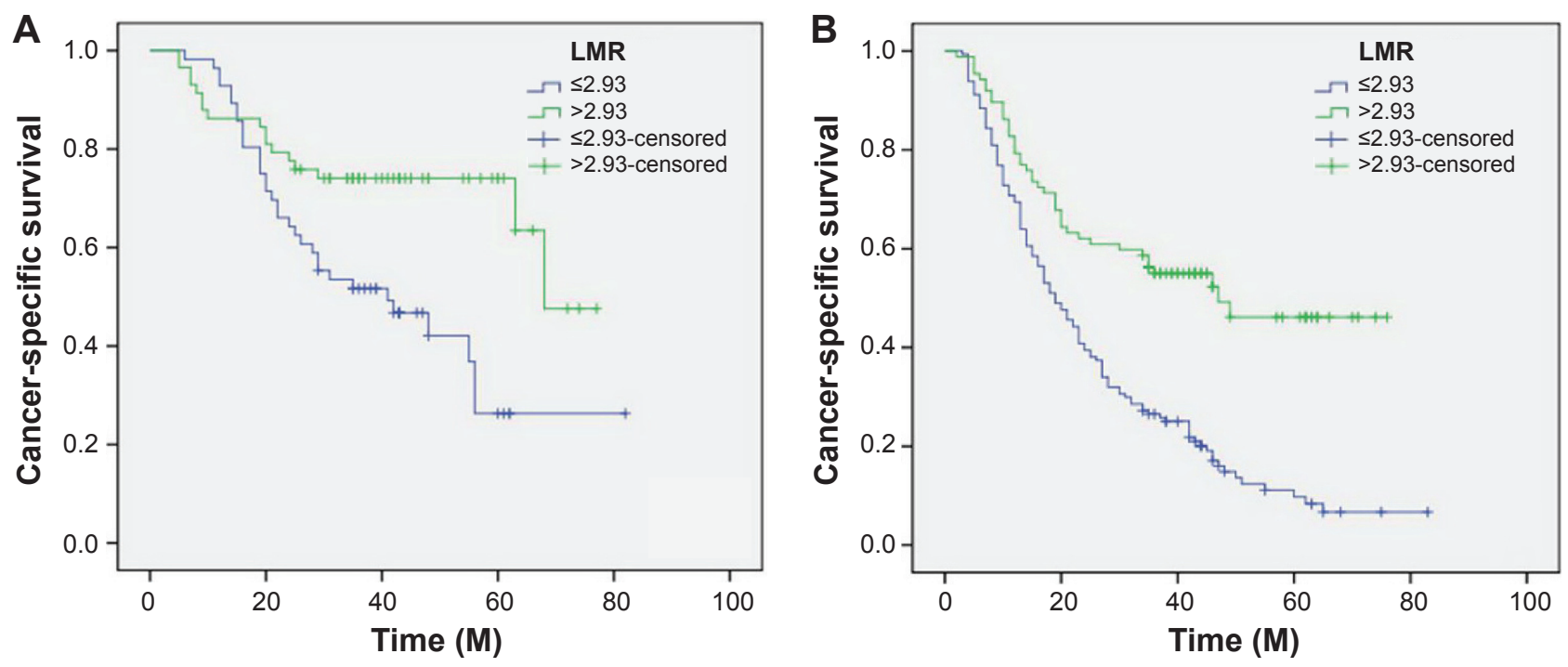

Figure 5 (Continued) 

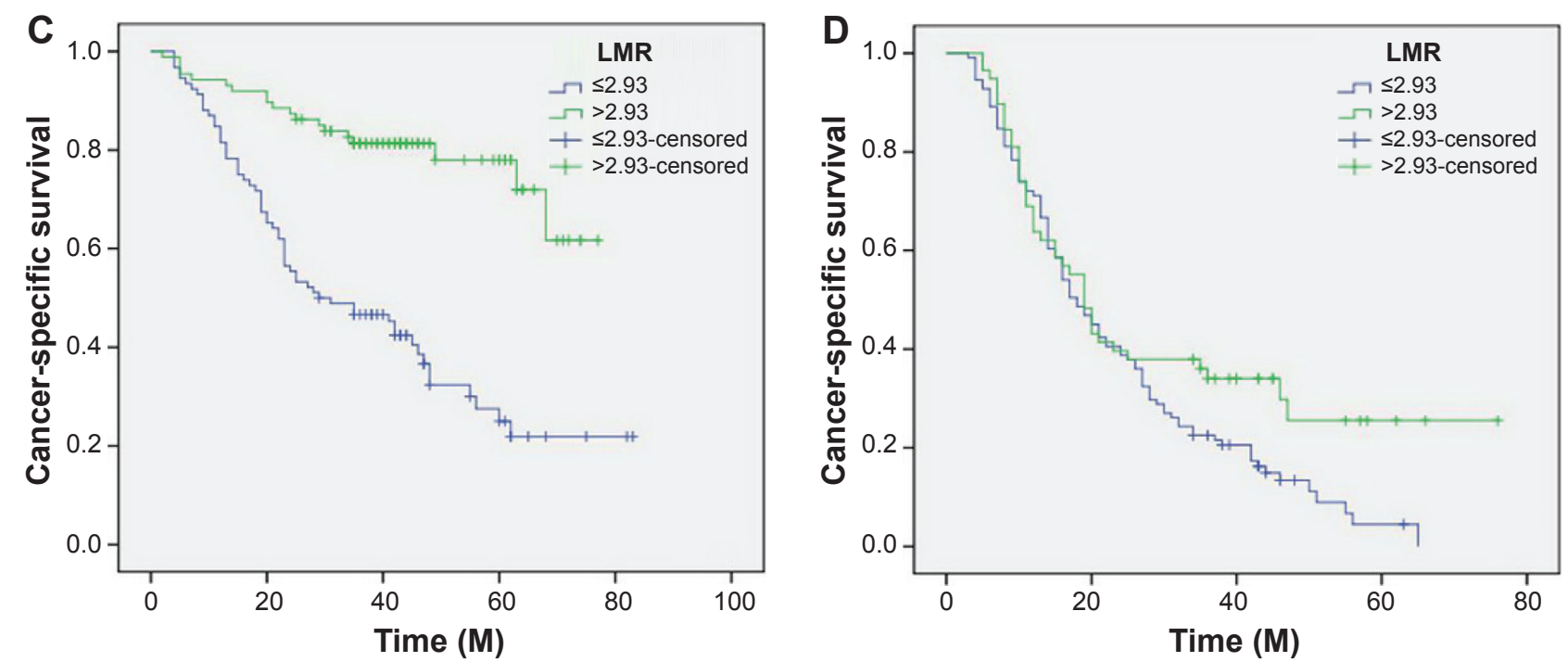

Figure 5 Kaplan-Meier CSS curves stratified by LMR in patients with TI-2 (A), T3-4a (B), and patients without (C) and with (D) nodal metastasis. Abbreviations: CSS, cancer-specific survival; LMR, lymphocyte to monocyte ratio; M, months.
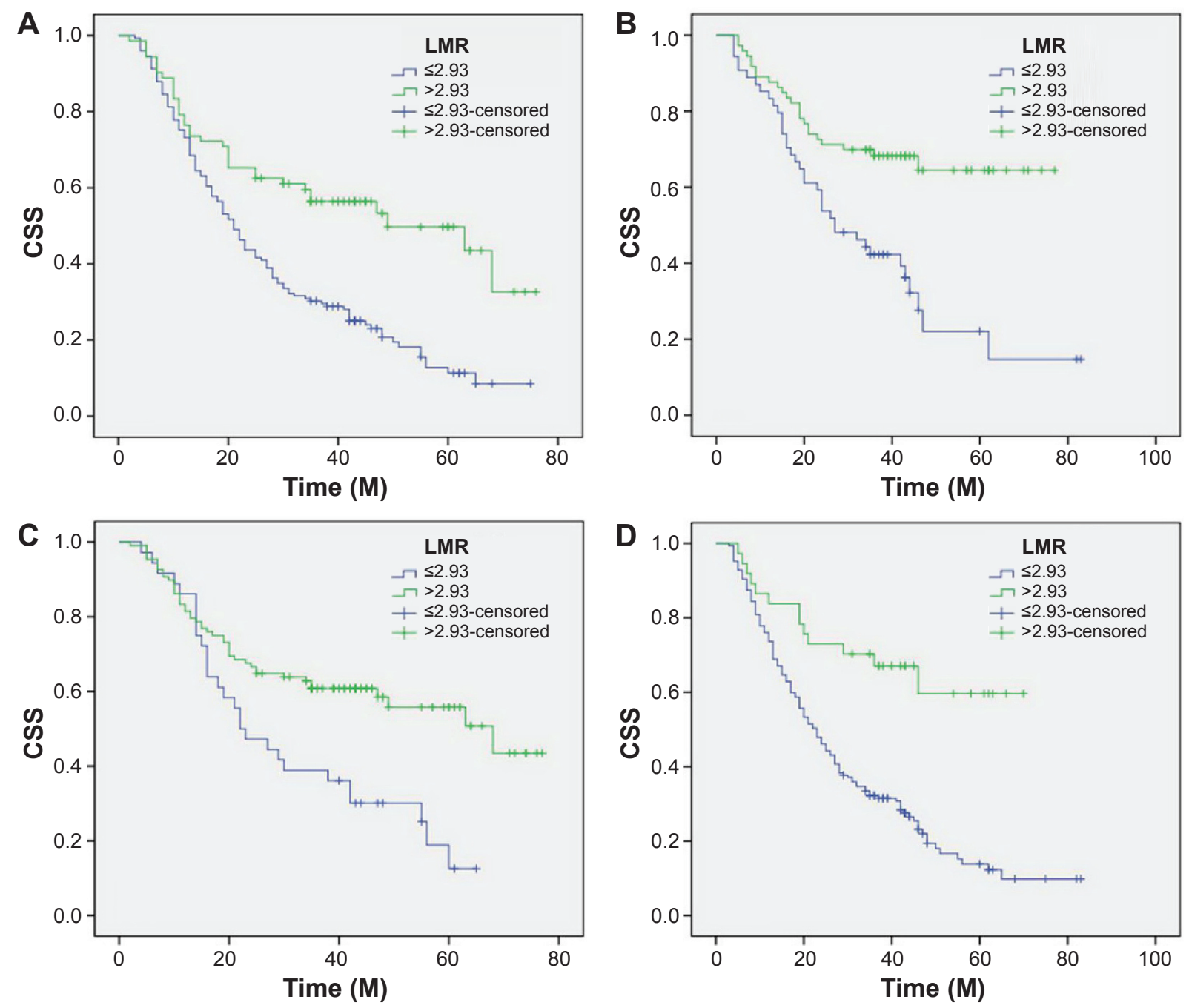

Figure 6 Kaplan-Meier CSS curves stratified by LMR in patients with ALC $\leq 1.75$ (A), ALC $>1.75$ (B), AMC $\leq 0.55$ (C), and AMC $>0.55$ (D).

Abbreviations: CSS, cancer-specific survival; ALC, absolute lymphocyte count; AMC, absolute monocyte count; LMR, lymphocyte to monocyte ratio; M, months. 
Table 3 Univariate and multivariate analyses of CSS in ESCC patients

\begin{tabular}{|c|c|c|c|c|}
\hline & Univariate analysis & $P$-value & Multivariate analysis & $P$-value \\
\hline & HR (95\% Cl) & & HR (95\% Cl) & \\
\hline Age (years) & & 0.720 & - & - \\
\hline$\leq 60$ & 1.000 & & & \\
\hline$>60$ & $1.050(0.804-1.372)$ & & & \\
\hline Sex & & 0.676 & - & - \\
\hline Female & 1.000 & & & \\
\hline Male & $1.090(0.728-1.630)$ & & & \\
\hline Tumor length $(\mathrm{cm})$ & & $<0.001$ & & 0.415 \\
\hline$\leq 3$ & 1.000 & & 1.000 & \\
\hline$>3$ & 1.921 (1.377-2.678) & & I.I 67 (0.805-1.690) & \\
\hline Tumor location & & 0.327 & - & - \\
\hline Upper/middle & 1.000 & & & \\
\hline Lower & I.I $42(0.876-1.488)$ & & & \\
\hline Vessel invasion & & $<0.001$ & & 0.190 \\
\hline Negative & 1.000 & & 1.000 & \\
\hline Positive & 1.909 (1.376-2.647) & & $1.262(0.89 \mid-1.789)$ & \\
\hline Differentiation & & 0.071 & - & - \\
\hline Well/moderate & 1.000 & & & \\
\hline Poor & $1.34 \mid(0.976-1.844)$ & & & \\
\hline Depth of invasion & & $<0.001$ & & 0.034 \\
\hline TI-2 & 1.000 & & 1.000 & \\
\hline T3-4a & $2.158(1.573-2.960)$ & & $1.475(1.030-2.113)$ & \\
\hline Nodal metastasis & & $<0.001$ & & $<0.001$ \\
\hline Negative & 1.000 & & 1.000 & \\
\hline Positive & $2.920(2.208-3.862)$ & & 2.156 (1.588-2.929) & \\
\hline Adjuvant therapy & & 0.403 & - & - \\
\hline No & 1.000 & & & \\
\hline Yes & $1.130(0.849-1.506)$ & & & \\
\hline $\operatorname{ALC}\left(\times 10^{9} / L\right)$ & & $<0.001$ & & 0.006 \\
\hline$\leq 1.75$ & 1.000 & & 1.000 & \\
\hline$>1.75$ & $0.570(0.424-0.767)$ & & $0.628(0.450-0.878)$ & \\
\hline AMC $\left(\times 10^{9} / L\right)$ & & 0.001 & & 0.173 \\
\hline$\leq 0.55$ & 1.000 & & 1.000 & \\
\hline$>0.55$ & 1.641 (1.239-2.173) & & $1.282(0.897-1.832)$ & \\
\hline LMR & & $<0.001$ & & 0.010 \\
\hline$\leq 2.93$ & 1.000 & & 1.000 & \\
\hline$>2.93$ & $0.394(0.292-0.532)$ & & $0.600(0.407-0.885)$ & \\
\hline
\end{tabular}

Abbreviations: CSS, cancer-specific survival; HR, hazard ratio; Cl, confidence interval; ESCC, esophageal squamous cell carcinoma; ALC, absolute lymphocyte count; AMC, absolute monocyte count; LMR, lymphocyte to monocyte ratio.

lymphocytes, and monocytes, were significantly associated with prognosis in various cancers. ${ }^{17,18}$ Hoffmann et al ${ }^{19}$ demonstrated that a low lymphocyte amount might be responsible for a weak, insufficient immunologic reaction. Furthermore, Evani et $\mathrm{al}^{20}$ showed that monocytes have a role in metastasis. Therefore, monocytes seem to promote tumor progression, in contrast to the role of lymphocytes.

In the present study, therefore, we initially evaluated the usefulness of LMR for predicting the postoperative CSS in patients with ESCC. Our study showed that LMR was associated with tumor length $(P=0.033)$, depth of invasion $(P=0.015)$, and nodal metastasis $(P=0.015)$. This observation is in line with data from Stotz et al ${ }^{11}$ but is contrary to the result of Lin et $\mathrm{al}^{13}$ who suggested that LMR is not correlated with the above factors. Furthermore, controversy exists concerning the optimal cut-off points for LMR to predict survival. In our study, therefore, an ROC curve for CSS prediction was plotted to verify the optimum cut-off point for LMR, which was 2.93. Our study showed that patients with LMR $\leq 2.93$ had a significantly worse 5-years CSS than patients with LMR $>2.93$. In multivariate analysis, LMR was a significant predictive factor of CSS.

It may well be that the influence of LMR on the subgroup with different $\mathrm{T}$ grades and $\mathrm{N}$ stagings is important for the understanding of its role in prognosis. In the further investigation, therefore, subgroup analysis was performed. In our 
study, the predictive value of LMR was also significant in patients with T1-2 cancer $(P=0.003)$, T3-4a $(P<0.001)$, and patients with $(P=0.044)$ or without $(P<0.001)$ nodal metastasis. In addition, the predictive value of LMR was also significantly stratified by ALC $(P<0.001)$ and AMC $(P<0.001)$. From the database of 348 patients with ESCC, our results clearly demonstrated that LMR can serve as an independent predictor of long-term survival for ESCC patients.

In conclusion, our study showed that LMR is associated with tumor progression and can be considered as an independent marker of prognosis in patients with ESCC. We conclude that 2.93 may be the optimum cut-off point for LMR in predicting survival in ESCC patients. However, larger prospective studies will need to be performed to confirm these preliminary results.

\section{Disclosure}

The authors report no conflicts of interest or financial disclosure in this work.

\section{References}

1. Ferlay J, Shin HR, Bray F, Forman D, Mathers C, Parkin DM. Estimates of worldwide burden of cancer in 2008: GLOBOCAN 2008. Int J Cancer. 2010;127(12):2893-2917.

2. Napier KJ, Scheerer M, Misra S. Esophageal cancer: A review of epidemiology, pathogenesis, staging workup and treatment modalities. World J Gastrointest Oncol. 2014;6(5):112-120.

3. Keditsu KK, Jiwnani S, Karimundackal G, Pramesh CS. Multimodality management of esophageal cancer. Indian J Surg Oncol. 2013;4(2): 96-104.

4. Lin Y, Totsuka Y, He Y, et al. Epidemiology of esophageal cancer in Japan and China. J Epidemiol. 2013;23(4):233-242.

5. Feng JF, Zhao Q, Chen QX. Prognostic value of subcarinal lymph node metastasis in patients with esophageal squamous cell carcinoma. Asian Pac J Cancer Prev. 2013;14(5):3183-3186.

6. Tachibana M, Kinugasa S, Hirahara N, Yoshimura H. Lymph node classification of esophageal squamous cell carcinoma and adenocarcinoma. Eur J Cardiothorac Surg. 2008;34(2):427-431.
7. Mantovani A, Allavena P, Sica A, Balkwill F. Cancer-related inflammation. Nature. 2008;454(7203):436-444.

8. Balkwill F, Mantovani A. Inflammation and cancer: back to Virchow? Lancet. 2001;357(9255):539-545.

9. Feng JF, Zhao Q, Chen QX. Prognostic significance of Glasgow prognostic score in patients undergoing esophagectomy for esophageal squamous cell carcinoma. Saudi J Gastroenterol. 2014;20(1): $48-53$.

10. Feng JF, Chen QX. Significance of the prognostic nutritional index in patients with esophageal squamous cell carcinoma. Ther Clin Risk Manag. 2014;10:1-7.

11. Stotz M, Pichler M, Absenger G, et al. The preoperative lymphocyte to monocyte ratio predicts clinical outcome in patients with stage III colon cancer. Br J Cancer. 2014;110(2):435-440.

12. Wei X, Huang F, Wei Y, et al. Low lymphocyte to monocyte ratio predicts unfavorable prognosis in non-germinal center type diffuse large B cell lymphoma. Leuk Res. 2014;38(6):694-698.

13. Lin GN, Peng JW, Xiao JJ, Liu DY, Xia ZJ. Prognostic impact of circulating monocytes and lymphocyte-to-monocyte ratio on previously untreated metastatic non-small cell lung cancer patients receiving platinum-based doublet. Med Oncol. 2014;31(7):70.

14. Vashist YK, Loos J, Dedow J, et al. Glasgow Prognostic Score is a predictor of perioperative and long-term outcome in patients with only surgically treated esophageal cancer. Ann Surg Oncol. 2011; 18(4):1130-1138.

15. Sato H, Tsubosa Y, Kawano T. Correlation between the pretherapeutic neutrophil to lymphocyte ratio and the pathologic response to neoadjuvant chemotherapy in patients with advanced esophageal cancer. World J Surg. 2012;36(3):617-622.

16. Sharaiha RZ, Halazun KJ, Mirza F, et al. Elevated preoperative neutrophil:lymphocyte ratio as a predictor of postoperative disease recurrence in esophageal cancer. Ann Surg Oncol. 2011;18(12): 3362-3369.

17. Schmidt H, Bastholt L, Geertsen $P$, et al. Elevated neutrophil and monocyte counts in peripheral blood are associated with poor survival in patients with metastatic melanoma: a prognostic model. Br J Cancer. 2005; 93(3):273-278.

18. Wilcox RA, Ristow K, Habermann TM, et al. The absolute monocyte count is associated with overall survival in patients newly diagnosed with follicular lymphoma. Leuk Lymphoma. 2012;53(4):575-580.

19. Hoffmann TK, Dworacki G, Tsukihiro T, et al. Spontaneous apoptosis of circulating $\mathrm{T}$ lymphocytes in patients with head and neck cancer and its clinical importance. Clin Cancer Res. 2002;8(8):2553-2562.

20. Evani SJ, Prabhu RG, Gnanaruban V, Finol EA, Ramasubramanian AK. Monocytes mediate metastatic breast tumor cell adhesion to endothelium under flow. FASEB J. 2013;27(8):3017-3029.
OncoTargets and Therapy

\section{Publish your work in this journal}

OncoTargets and Therapy is an international, peer-reviewed, open access journal focusing on the pathological basis of all cancers, potential targets for therapy and treatment protocols employed to improve the management of cancer patients. The journal also focuses on the impact of management programs and new therapeutic agents and protocols on

\section{Dovepress}

patient perspectives such as quality of life, adherence and satisfaction. The manuscript management system is completely online and includes a very quick and fair peer-review system, which is all easy to use. Visit http://www.dovepress.com/testimonials.php to read real quotes from published authors. 